\title{
Importance of light smoking and inhalation habits on risk of myocardial infarction and all cause mortality. A 22 year follow up of 12149 men and women in The Copenhagen City Heart Study
}

\author{
E Prescott, H Scharling, M Osler, P Schnohr
}

J Epidemiol Community Health 2002;56:702-706

See end of article for authors' affiliations

Correspondence to: Dr E Prescott, Institute of Preventive Medicine, Kommunehospitalet, DK-1399, Copenhagen,

Denmark;

eva.prescott@dadlnet.dk

Accepted for publication 17 December 2001

\begin{abstract}
Study objective: To determine risk of myocardial infarction (MI) and all cause mortality associated with light smoking and inhalation habits in men and women.

Design: Prospective cohort study with follow up of $\mathrm{Ml}$ and all cause mortality through record linkage. Setting: The Copenhagen City Heart Study, a cardiovascular study based on a sample of the general population established in 1976.

Participants: 6505 women and 5644 men followed up until 1998 for first $\mathrm{Ml}$ and for death from all causes.

Main results: During follow up 476 women and 872 men suffered a MI whereas 2305 women and 2883 men died. After adjusting for major cardiovascular risk factors there was a dose-response relation between smoking with and without inhaling and both $\mathrm{Ml}$ and all cause mortality. Among inhaling smokers significantly increased risks were found in women at a consumption of only 3-5 grams of tobacco per day with relative risks (RR) of $\mathrm{Ml}$ and all cause mortality of $2.14(95 \% \mathrm{Cl} 1.11$ to 4.13$)$ and $1.86(95 \% \mathrm{Cl} 1.37$ to 2.51$)$, respectively. In men increased risks were seen when smoking 6-9 grams per day with RR of $\mathrm{Ml}$ and all cause mortality of $2.10(95 \% \mathrm{Cl} 1.40$ to 3.14$)$ and $1.76(95 \%$ $\mathrm{Cl} 1.39$ to 2.23$)$, respectively. Risks were also increased in non-inhaling smokers, although in men only significantly so for all cause mortality. After adjusting for inhalation and quantity smoked, cigarette smokers had a higher risk of all cause mortality (RR $1.16(95 \% \mathrm{Cl} 1.07$ to 1.26$)$ ) but not of MI (RR 1.11 (95\% $\mathrm{Cl} 0.95$ to 1.30$)$ ). The RR associated with smoking were significantly higher in women than in men for both $\mathrm{MI}$ and all cause mortality.

Conclusions: Smoking as little as 3-5 grams of tobacco per day or not inhaling the smoke was shown to carry a significantly increased risk of developing $\mathrm{Ml}$ and of all cause mortality with higher RR found in women than in men. The study emphasises the importance of recognising that even very limited tobacco consumption has detrimental health effects.
\end{abstract}

A though the hazards of smoking are well described, among smokers it is often assumed that consumption of a few cigarettes, or smoking without inhaling the smoke is not hazardous. From a public health as well as a clinical point of view it is important to recognise health hazards associated with a small consumption to adequately advise on smoking.

The risk of myocardial infarction (MI) and all cause mortality increases with increasing tobacco consumption but most previous studies have used a cut off point of 10, 15, or 20 cigarettes per day. ${ }^{1-3}$ Establishing the hazards of light smoking with sufficient accuracy requires large population studies and only few studies have attempted this. ${ }^{4-6}$ To our knowledge, no study has described the risk associated with smoking without inhaling.

The Copenhagen city heart study has since 1976 followed up 14223 persons with an unusually large proportion of smokers among both men and women. Until the end of 1997, 5188 deaths and 1348 cases of MI had been registered, and the study now offers the opportunity to examine the effects of light smoking and smoking without inhaling the smoke on risk of developing $\mathrm{MI}$ and on all cause mortality.

\section{METHODS}

\section{Population and design}

We used data from the Copenhagen city heart study, which has previously been described in detail. ${ }^{7}$ In summary, the population was derived from a random, age stratified sample of 19698 people aged 20 years or more recruited among 90000 people living in a defined area in Copenhagen. A total of 14223 subjects (response rate $72 \%$ ) attended the first examination in 1976/78. Subjects were followed up until 31 December 1997 for fatal and non-fatal MI (ICD-8 diagnosis code 410 until 1 January 1994, ICD-10 diagnosis codes I21 and I22 from 1994 onwards) obtained from the National Board of Health and the National Hospital Discharge Register, respectively. Subjects with self reported and verified ischaemic heart disease (IHD) before enrolment were excluded and analyses therefore concern first MI only. In addition, only subjects above age 30 were included to ensure that smoking habits were established at baseline. All subjects with sufficient information on cardiovascular risk factors were included.

\section{Variables of interest}

Cardiovascular risk factors were assessed by a self administered questionnaire and by various laboratory tests. The participants gave information on smoking status as never smokers, ex-smokers, or current smokers. Current smokers reported amount and type (cigarettes, cheroots, cigars, pipe, or

Abbreviations: $\mathrm{MI}$, myocardial infarction; IHD, ischaemic heart disease 
Table 1 Baseline characteristics and risk factors in 6505 women and 5644 men in the Copenhagen City Heart Study in 1976. Values are means (SD) or number (\%)

\begin{tabular}{llll}
\hline & Women $\mathrm{n}=6505$ & Men $\mathrm{n}=5644$ & $\mathrm{p}$ Value* \\
\hline Age (years) & $54.0(10.4)$ & $54.3(11.1)$ & $\mathrm{p}=0.20$ \\
Body mass index $\left(\mathrm{kg} / \mathrm{m}^{2}\right)$ & $24.75(4.42)$ & $25.90(3.67)$ & $<0.0001$ \\
Systolic blood pressure $(\mathrm{mm} \mathrm{Hg})$ & $135.7(22.3)$ & $140.7(20.7)$ & $<0.0001$ \\
Diastolic blood pressure $(\mathrm{mm} \mathrm{Hg})$ & $81.7(11.5)$ & $85.3(12.5)$ & $<0.0001$ \\
Total cholesterol (mmol/I) & $6.31(1.27)$ & $5.99(1.13)$ & $<0.0001$ \\
Plasma triglyceride (mmol/I) & $1.50(0.89)$ & $2.10(1.47)$ & $<0.0001$ \\
School education (<1 1 years) & $5772(88.7)$ & $4659(84.3)$ & $<0.0001$ \\
Household income (lowest category) & $2099(32.3)$ & $1159(20.5)$ & $<0.0001$ \\
Physically active (>4 hours per week) & $1390(21.3)$ & $1726(30.6)$ & $<0.0001$ \\
Alcohol intake (<7 drinks/week) & $5705(87.7)$ & $3145(55.7)$ & $<0.0001$ \\
Self reported diabetes & $116(1.8)$ & $234(4.2)$ & $<0.0001$ \\
Family history of Ml & $1291(19.9)$ & $848(15.0)$ & $<0.0001$ \\
\hline \multirow{2}{*}{ *For continuous data from analyses of variance. For categorical data $\chi^{2}$ test (with more categories than given } \\
in the table).
\end{tabular}

Table 2 Smoking characteristics at baseline in 6505 women and 5644 men in the Copenhagen City Heart Study in 1976. Values are means (SD) or number (\%)

\begin{tabular}{|c|c|c|c|c|}
\hline & \multicolumn{2}{|c|}{ Women $n=6505$} & \multicolumn{2}{|l|}{ Men $n=5644$} \\
\hline Never smokers & $1811(27.8)$ & & $555(9.8)$ & \\
\hline Ex-smokers & $952(14.6)$ & & $1115(19.8)$ & \\
\hline Current smokers & $3742(57.5)$ & & $3974(70.4)$ & \\
\hline \multicolumn{5}{|c|}{ Type of tobacco among current smokers* } \\
\hline Cigarettes & $3040(81.2)$ & & $2258(56.8)$ & \\
\hline Cigars & $10(0.3)$ & & $100(2.5)$ & \\
\hline Cheroots & $642(17.2)$ & & $546(13.7)$ & \\
\hline Pipe & $5(0.1)$ & & 389 (9.8) & \\
\hline Mixed & $45(1.2)$ & & $681(17.1)$ & \\
\hline Daily consumption* & non-inhalers & inhalers & non-inhalers & inhalers \\
\hline$<3 \mathrm{~g} /$ day & $74(2.0)$ & $34(0.9)$ & $11(0.3)$ & $20(0.5)$ \\
\hline $3-5 \mathrm{~g} /$ day & $187(5.0)$ & $162(4.3)$ & $68(1.7)$ & $88(2.2)$ \\
\hline $6-9 \mathrm{~g} /$ day & $253(6.8)$ & 227 (6.1) & 149 (3.7) & $190(4.8)$ \\
\hline $10-14 \mathrm{~g} /$ day & $207(5.5)$ & $836(22.3)$ & $189(4.8)$ & 635 (16.0) \\
\hline $15-24 \mathrm{~g} /$ day & $324(8.7)$ & $1180(31.5)$ & $295(7.4)$ & 1499 (37.7) \\
\hline$\geqslant 25 \mathrm{~g} /$ day & $93(2.5)$ & $165(4.4)$ & 195 (4.9) & 635 (16.0) \\
\hline All current smokers* & $1138(30.4)$ & $2604(69.6)$ & $907(22.8)$ & 3067 (77.2) \\
\hline
\end{tabular}

mixed) of tobacco presently smoked and whether he or she inhaled. Current tobacco consumption was calculated by equating a cigarette to 1 gram, a cheroot to 3 grams, and a cigar to 5 grams of tobacco.

Arterial blood pressure was measured in a sedentary position after at least five minutes' rest and was analysed in five categories: systolic blood pressure $(\mathrm{SBP})<140$ and diastolic blood pressure $(\mathrm{DBP})<90 ; 140 \leqslant \mathrm{SBP}<160$ or $90 \leqslant \mathrm{DBP}<100$; $160 \leqslant \mathrm{SBP}<180$ or $100 \leqslant \mathrm{DBP}<110 ; 180 \leqslant \mathrm{SBP}$ or $110 \leqslant \mathrm{DBP}$, and; taking anti-hypertension medication. Blood lipids were measured non-fasting. Total cholesterol was divided into three categories: less than 5; 5-7, and; $7 \mathrm{mmol} / \mathrm{l}$ or more. Triglycerides were also divided into three categories: less than $1 ; 1-3$, and; $3 \mathrm{mmol} / \mathrm{l}$ or more. Body mass index (BMI) was calculated as weight $(\mathrm{kg})$ divided by height squared $\left(\mathrm{m}^{2}\right)$ and analysed in four categories: less than $20 ; 20-25 ; 25-30$, and; $30 \mathrm{~kg} / \mathrm{m}^{2}$ or more. Two socioeconomic status variables were included: educational level, which was divided into three categories: less than eight years of schooling (completed primary school); 8-10 years, and; more than 10 years, as well as household income categorised as low, medium or high income. Alcohol consumption was classified according to daily intake in: less than one drink per day; 1-2; 3-4; and more than 4 drinks per day, one drink containing 9-13 g alcohol. Physical activity in leisure time was classified as sedentary; moderate activity less than four hours; and moderate activity more than four hours per week. Diabetes and family history of MI were also self reported.

\section{Statistical analyses}

To assess the independent contribution of smoking to MI and all cause mortality, the Cox proportional hazards model was used ${ }^{8}$ with age as underlying timescale and delayed entry accordingly. Analyses were performed separately by gender and were adjusted for confounders as indicated. Using age as underlying timescale ensured optimal adjustment for age. All covariates were treated as categorical variables as described above and tests for interaction were done using the likelihood ratio test. The assumption of proportional hazards was tested by interaction terms with age using the likelihood ratio test. All results given were adjusted for the cardiovascular risk factors listed in table 1. After five years 11094 subjects were re-examined. Repeated analyses using the updated smoking habits whenever possible did not affect the risk estimates and results shown are therefore based on smoking habits at baseline.

Data were analysed using STATA. ${ }^{9}$ The results of regression analyses are given in terms of estimated relative risks (hazard ratios) with their corresponding 95\% confidence intervals.

\section{RESULTS}

After excluding 1207 women and 867 men because of age below $30(n=610)$, IHD before the study entry $(n=298)$, or missing data on one or more variables $(n=1166)$, there were 6505 women and 5644 men available for analyses. For each covariate less than approximately 100 subjects within each sex had missing data except for household income, which 455 
Table 3 Adjusted* relative risk (95\% confidence interval) of myocardial infarction by tobacco consumption in 6505 women and 5644 men in the Copenhagen City Heart Study. Results from Cox proportional hazard regression analyses

\begin{tabular}{|c|c|c|c|c|c|c|}
\hline & \multicolumn{3}{|l|}{ Women } & \multicolumn{3}{|l|}{ Men } \\
\hline & Events (n) & $R R$ & $95 \% \mathrm{Cl}$ & Events (n) & RR & $95 \% \mathrm{Cl}$ \\
\hline Never smokers & 107 & ref & & 62 & ref & \\
\hline Ex-smokers & 42 & 0.83 & 0.58 to 1.19 & 170 & 1.10 & 0.82 to 1.47 \\
\hline \multicolumn{7}{|l|}{ Non-inhalers } \\
\hline$<3 \mathrm{~g} /$ day & 3 & 0.90 & 0.28 to 2.86 & 2 & 2.03 & 0.49 to 8.30 \\
\hline $3-5 \mathrm{~g} /$ day & 13 & 1.07 & 0.60 to 1.92 & 11 & 1.28 & 0.67 to 2.45 \\
\hline $6-9 \mathrm{~g} /$ day & 26 & 1.58 & 1.03 to 2.43 & 21 & 0.87 & 0.53 to 1.44 \\
\hline $10-14 \mathrm{~g} /$ day & 23 & 2.00 & 1.27 to 3.15 & 31 & 1.30 & 0.84 to 2.00 \\
\hline $15-24 \mathrm{~g} /$ day & 35 & 1.87 & 1.27 to 2.74 & 55 & 1.39 & 0.96 to 2.01 \\
\hline$>24 \mathrm{~g} /$ day & 9 & 1.92 & 0.97 to 3.82 & 26 & 1.11 & 0.70 to 1.76 \\
\hline Test for trend & & $p<0.001$ & & & $p=0.19$ & \\
\hline \multicolumn{7}{|l|}{ Inhalers } \\
\hline$<3 \mathrm{~g} /$ day & 2 & 1.40 & 0.34 to 5.70 & 2 & 0.76 & 0.19 to 3.13 \\
\hline $3-5 \mathrm{~g} /$ day & 10 & 2.14 & 1.11 to 4.13 & 10 & 1.03 & 0.53 to 2.01 \\
\hline 6-9 g/day & 21 & 2.44 & 1.52 to 3.93 & 39 & 2.10 & 1.40 to 3.14 \\
\hline $10-14 \mathrm{~g} /$ day & 79 & 3.08 & 2.26 to 4.18 & 115 & 1.68 & 1.23 to 2.30 \\
\hline $15-24 \mathrm{~g} /$ day & 94 & 3.15 & 2.33 to 4.25 & 228 & 1.61 & 1.21 to 2.15 \\
\hline$>24 \mathrm{~g} /$ day & 12 & 3.45 & 1.86 to 6.39 & 100 & 1.96 & 1.41 to 2.71 \\
\hline Test for trend & & $p<0.001$ & & & $p<0.001$ & \\
\hline Total number of events & \multicolumn{3}{|l|}{476} & \multicolumn{3}{|l|}{872} \\
\hline
\end{tabular}

*Adjusted for age, systolic and diastolic blood pressure, BMI, total cholesterol, triglyceride, school education, household income, physical activity, alcohol intake, self reported diabetes, and family history of $\mathrm{MI}$.

Table 4 Adjusted* relative risk (95\% confidence intervals) of all cause mortality by tobacco consumption in 6505 women and 5644 men in the Copenhagen City Heart Study. Results from Cox proportional hazard regression analyses

\begin{tabular}{|c|c|c|c|c|c|c|}
\hline & \multicolumn{3}{|l|}{ Women } & \multicolumn{3}{|l|}{ Men } \\
\hline & Events (n) & RR & $95 \% \mathrm{Cl}$ & Events (n) & $R R$ & $95 \% \mathrm{Cl}$ \\
\hline Never smokers & 572 & ref & & 200 & ref & \\
\hline Ex-smokers & 288 & 1.16 & 1.00 to 1.33 & 551 & 1.00 & 0.85 to 1.18 \\
\hline \multicolumn{7}{|l|}{ Non-inhalers } \\
\hline$<3$ g per day & 20 & 1.24 & 0.79 to 1.94 & 4 & 1.32 & 0.49 to 3.56 \\
\hline $3-5$ g per day & 69 & 1.17 & 0.91 to 1.50 & 37 & 0.99 & 0.70 to 1.42 \\
\hline 6-9 g per day & 109 & 1.24 & 1.01 to 1.53 & 80 & 0.86 & 0.67 to 1.13 \\
\hline $10-14 \mathrm{~g}$ per day & 96 & 1.62 & 1.30 to 2.02 & 119 & 1.19 & 0.95 to 1.50 \\
\hline $15-24 \mathrm{~g}$ per day & 156 & 1.57 & 1.31 to 1.88 & 183 & 1.17 & 0.96 to 1.44 \\
\hline$>24 \mathrm{~g}$ per day & 47 & 1.71 & 1.26 to 2.31 & 114 & 1.24 & 0.97 to 1.56 \\
\hline Test for trend & & $p<0.001$ & & & $p<0.03$ & \\
\hline \multicolumn{7}{|l|}{ Inhalers } \\
\hline$<3$ g per day & 8 & 1.10 & 0.54 to 2.21 & 6 & 0.55 & 0.25 to 1.25 \\
\hline $3-5$ g per day & 46 & 1.86 & 1.37 to 2.51 & 36 & 1.24 & 0.87 to 1.78 \\
\hline 6-9 g per day & 83 & 1.86 & 1.47 to 2.35 & 107 & 1.76 & 1.39 to 2.23 \\
\hline $10-14 \mathrm{~g}$ per day & 304 & 2.41 & 2.07 to 2.79 & 315 & 1.52 & 1.27 to 1.82 \\
\hline 15-24 g per day & 424 & 2.87 & 2.51 to 3.30 & 803 & 1.98 & 1.69 to 2.32 \\
\hline$>24 \mathrm{~g}$ per day & 83 & 4.58 & 3.60 to 5.83 & 328 & 2.17 & 1.81 to 2.60 \\
\hline Test for trend & & $p<0.001$ & & & $p<0.001$ & \\
\hline Total number of events & \multicolumn{3}{|l|}{2305} & \multicolumn{3}{|l|}{2883} \\
\hline
\end{tabular}

*Adjusted for age, systolic and diastolic blood pressure, BMI, total cholesterol, triglyceride, school education, household income, physical activity, alcohol intake, self reported diabetes, and family history of $\mathrm{Ml}$.

women did not report. Only 37 men and 36 women did not report their smoking habits. During follow up 476 women and 872 men suffered a MI of which $40 \%$ were fatal ( 182 women, 362 men). A total of 2305 women and 2883 men died of all causes.

Baseline characteristics of the participants at study entry with emphasis on cardiovascular risk factors are shown in table 1. With the exception of age, men and women differed in all variables. Men had a more beneficial risk factor profile as far as total cholesterol, alcohol consumption, physical activity, family history, household income, and education whereas women had more advantageous triglyceride, blood pressure,
BMI, and history of diabetes. Details of smoking characteristics are given in table 2 . There were more male smokers, they smoked more and proportion of inhalers was greater. Number of male smokers with a light consumption of tobacco was limited, in particular number of non-inhalers. Type of tobacco smoked differed by gender with $81.2 \%$ of women and $56.8 \%$ of men being cigarette smokers. Distribution of smoking habits among the 1166 subjects excluded because of missing data did not differ from smoking habits among the remaining.

Table 3 gives RR of myocardial infarction by daily tobacco consumption in inhaling and non-inhaling current smokers for men and women separately adjusted for the risk factors 
listed in table 1. In both men and women risks were significantly higher in smokers, who claimed to inhale than in smokers, who did not. Overall effect of inhalation in women was 1.65 ( 1.28 to 2.13 ) and in men was 1.39 ( 1.14 to 1.70 ). In women, significantly increased risks were found for consumption of 6 grams of tobacco per day or more in non-inhalers and for 3 grams or more in inhalers. In male smokers who inhaled, risks were significantly increased for a consumption of 6 grams of tobacco per day or more. Risks were not significantly increased in any of the categories of non-inhalers in men and test for linear trend was also insignificant $(p=0.19)$.

$\mathrm{RR}$ associated with smoking were higher in women than in men. In a model adjusting for quantity smoked (three categories), inhalation and type of tobacco, in addition to the cardiovascular risk factors listed in table 1 , interaction between gender and smoking was highly significant with higher relative risks found in female smokers as compared with male smokers. The female-male ratio of RR associated with smoking was 1.72 ( 1.19 to 2.47 ) in inhaling smokers; 1.47 (0.92 to 2.08) in non-inhaling smokers; and 0.78 (0.49 to 1.24) in ex-smokers (likelihood ratios test for interaction: $\mathrm{p}=0.0001$ ). Risk did not differ significantly with type of tobacco smoked: RR for cigarette smokers versus non-cigarette smokers was 1.11 (0.95 to 1.30). The effect of quantity smoked was not modified by type of tobacco.

Blood pressure, total cholesterol, triglyceride, education, household income, alcohol intake, leisure time physical activity, a family history of MI and diabetes, but not BMI, were strongly associated with risk of MI. With the exception of smoking, triglyceride and diabetes, which were stronger predictors of MI in women than in men, RR were similar in men and women.

Similar analyses were performed with all cause mortality as end point (table 4). RR were higher in inhaling smokers than in non-inhaling smokers. RR associated with inhalation was 1.70 ( 1.50 to 1.91$)$ and 1.60 ( 1.44 to 1.78$)$ in women and men, respectively. In women $\mathrm{RR}$ were significantly increased in non-inhalers smoking 6 grams of tobacco per day or more and in inhalers smoking 3 grams or more. In men significantly increased risks were seen in inhaling smokers who smoked 6 grams per day or more. Risks were not significantly increased in any of the categories of non-inhalers, but a significant trend was found $(\mathrm{p}=0.03)$.

As was seen for MI, RR were higher in women smokers than in men, particularly so in inhaling smokers. The ratio between risk in men and women was 1.44 (1.19 to 1.74) in inhaling smokers; 1.27 (1.04 to 1.56) in non-inhaling smokers; and 1.14 (0.92 to 1.42 ) in ex-smokers (likelihood ratio test for interaction, $\mathrm{p}=0.0008)$. Risk was higher in cigarette smokers than in smokers of other types of tobacco: RR 1.16 (1.07 to 1.26). There was no effect modification between type of tobacco and quantity smoked. With the exception of family predisposition for MI in both genders and increased triglyceride in men, the risk factors given in table 1 were all found to be significant predictors of all cause mortality.

Analyses were repeated including the 1093 subjects with missing data on confounders other than smoking habits, giving a total of 7257 women and 5985. Results adjusting only for age did not differ from the unadjusted results for the restricted sample reported on above.

\section{DISCUSSION}

In this prospective study of approximately 12000 subjects followed up for almost 22 years, the main results were that smoking down to 3 grams of tobacco per day for women and 6 grams per day for men was associated with a significantly increased risk of both MI and all cause mortality. Significant interaction between smoking and gender was found with RR approximately 50\% higher in female smokers compared with male smokers for MI and all cause mortality.

\section{Key points}

- Although the effects of smoking are well known, smokers often assume that smoking just a few cigarettes or smoking without inhaling is not hazardous.

- In this study smoking without inhaling was associated with a significantly increased risk of myocardial infarction and all cause mortality.

- Smoking as little as 3 to 5 grams of tobacco was associated with significantly increased risks.

- Relative risks associated with smoking were significantly higher in women than in men.

- The study emphasises that even very limited tobacco consumption has detrimental health effects.

MI was ascertained from the Hospital Discharge Register and from registration of cause of death in the National Board of Health, and included both fatal and non-fatal MI. Some infarctions have not led to hospital admission or may have been coded differently. However, only differential misclassification-that is, in this case related to smoking habits-will bias the results and there is no reason to suspect this, in particular as results for mortality were similar to results on risk of MI. Another potential cause of error is that smoking habits are likely to have changed during the long follow up. However, the most probable change in subjects of this age group is quitting smoking and not adjusting for this would cause us to underestimate risk associated with smoking rather than the reverse. In addition, the repeated analyses using updated smoking habits when available did not affect results.

Many smokers believe that as long as they do not inhale the smoke, smoking is not hazardous. Furthermore, epidemiological studies seldom take into account inhalation habits, perhaps in part because of an implicit understanding that smokers do inhale, whether they admit to it or not. In this study a large proportion of the smokers said they were non-inhalers, many of them non-cigarette smokers in older generations. Smokers, who did not inhale had RR that were intermediary between never smokers and inhalers: noninhaling female smokers who smoked more than 10 grams of tobacco per day have twice the risk of MI and $60 \%$ higher mortality risk compared with never smokers. In non-inhaling male smokers RR were higher than in never smokers but did not reach statistical significance although a significant trend was seen for all cause mortality.

In current inhaling smokers there was a clear dose-response relation between amount smoked and risk of MI and all cause mortality with significantly increased risks found at a daily consumption down to 3-5 grams of tobacco per day in women and 6-9 grams of tobacco per day in men. Below this consumption risks could not be shown to differ from risk in never smokers but confidence intervals were wide and the study does not establish a lower threshold limit for when smoking is damaging. Cigarette smokers were at somewhat higher risk than non-cigarette smokers, although only significantly so for all cause mortality, but the effect of quantity smoked did not differ. Unfortunately, data were not sufficient to separately study the effect of smoking cigars, cheroots, and pipe.

Few studies have reported risk associated with very light smoking, presumably because of the methodological problems mentioned. In a Swedish study of 6879 middle aged men, smoking 1-4 cigarettes daily was associated with a significantly increased risk of suffering a CHD event with an odds ratio of 2.8 ( 1.7 to 4.7 ). ${ }^{5}$ In the Nurses Health Study female smokers of 1-4 cigarettes per day had an unadjusted RR of 2.4 ( 1.1 to 5.0) of developing CHD. ${ }^{4}$ In a Danish study where men and women were pooled, risk of MI was insignificantly increased in smokers of $1-5$ grams of tobacco per day (RR 1.61 $(0.62$ to 4.18$)){ }^{6}$ 
We have previously shown that female smokers have approximately $50 \%$ higher relative risk of developing $\mathrm{MI}^{10}$ and also higher relative mortality risk from vascular disease. ${ }^{11}$ The present study has confirmed that there is a gender difference in smoking related vascular morbidity and extended the finding to a significant difference in all cause mortality. A few other studies have found higher RR in women smokers. ${ }^{212-15}$ These studies were all recent and were based on populations with high prevalence of female smokers. Other studies may not have found gender differences in risk associated with smoking ${ }^{13}{ }^{16-19}$ because of the extensive differences in smoking habits between male and female smokers from older birth cohorts. It has been suggested that with high prevalence of smoking, risk associated with smoking may be underestimated because of a healthy smoker effect-that is, in a society where smoking prevails, predominantly unhealthy individuals will refrain from smoking. With the very high prevalence of ever smokers seen in men in this population study this could be a cause of the difference in risk estimates in men and women. However, the differences were of equal size among younger subjects in whom prevalence of smoking was more similar in men and women indicating that this did not cause the difference. A biological explanation may be that because of the anti-oestrogenic effect of smoking ${ }^{20}{ }^{20}$ women smokers are twice "struck": smoking increases risk of IHD through atherosclerosis and haemostatic factors, as it does in men, but in women it also exerts deleterious effects through the anti-oestrogenic effect that renders women smokers less protected from IHD than their non-smoking counterparts. An additional factor in the higher RR of all cause mortality is that women have been shown to be more susceptible to respiratory disease, particularly chronic obstructive pulmonary disease. ${ }^{21}{ }^{22}$ However, risk estimates in this study are relative and do not correspond to increased absolute risks as the baseline risks of women are smaller than those of men.

In conclusion, we find that smoking without inhaling or smoking as little as $\mathbf{3} \mathbf{- 5}$ grams of tobacco per day is associated with a significantly increased risk of developing myocardial infarction and of all cause mortality and this risk is higher in women than in men. Although from a toxicology point of view it is not surprising that the dose-response relation between smoking and morbidity does not have a lower threshold limit, from a public health point of view it is important to recognise the increased risk associated with even a low consumption of tobacco.

\section{Authors' affiliations}

E Prescott, Danish Epidemiology Science Centre at the Institute of Preventive Medicine, University of Copenhagen, Denmark H Scharling, P Schnohr, Copenhagen City Heart Study, Bispebjerg Hospital, University of Copenhagen, Denmark

M Osler, Institute of Public Health, University of Copenhagen, Denmark
Funding: this study was supported by The Danish Heart Foundation and The Danish Ministry of Health.

Conflicts of interest: none.

\section{REFERENCES}

1 Tverdal A, Thelle D, Stensvold I, et al. Mortality in relation to smoking history: 13 years' follow-up of 68,000 Norwegian men and women 35-49 years. J Clin Epidemiol 1993;46:475-87.

2 Niolstad I, Arnesen E, Lund Larsen PG. Smoking, serum lipids, blood pressure, and sex differences in myocardial infarction. A 12-year follow-up of the Finnmark Study. Circulation 1996:93:450-6.

3 Doll R, Peto R, Wheatley K, et al. Mortality in relation to smoking: 40 years' observations on male British doctors. BM 1994;309:901-11.

4 Willett WC, Green A, Stampfer M, et al. Relative and absolute excess risks of coronary heart disease among women who smoke cigarettes. $N$ Engl J Med 1987;317:1303-9

5 Rosengren A, Wilhelmsen L, Wedel $\mathrm{H}$. Coronary heart disease, cancer and mortality in male middle-aged light smokers. J Intern Med 1992;231:357-62.

6 Kirchhoff $M$, Schroll M, Hagerup L, et al. Smoking habits and risk of coronary heart disease, especially risk associated with low daily tobacco consumption (English summary). Ugeskr Læger 1993;155:718-21.

7 Appleyard M, Hansen AT, Schnohr P, et al. The Copenhagen City Heart Study. A book of tables with data from the first examination (1976-78) and a 5-year follow-up (1981-83). Scand J Soc Med 1989;170:1-160.

8 Cox DR. Regression models and life-tables. Journal of the Royal Statistical Society 1972;B 34:187-220.

9 StataCorp. Stata statistical software: Release 5.0. College Station, TX: Stata Corporation, 1997.

10 Prescott $E$, Hippe M, Schnohr $P$, et al. Smoking and risk of myocardial infarction in women and men: longitudinal population study. BM 1998;316:1043-6.

11 Prescott E, Osler M, Andersen PK, et al. Mortality in women and men in relation to smoking. Int J Epidemiol 1998;27:27-32.

12 Janghorbani $\mathbf{M}$, Hedley AJ, Jones RB, et al. Gender differential in all-cause and cardiovascular disease mortality. Int J Epidemiol 1993;22:1056-63.

13 Floderus B, Cederlöf R, Friberg L. Smoking and mortality: a 21 -year follow-up based on the swedish twin registry. Int J Epidemio 1988; 17:332-40.

14 McElduff P, Dobson A, Beaglehole R, et al. Rapid reduction in coronary risk for those who quit cigarette smoking. Aust N Z J Public Health 1998;22:787-91

15 Woodward M, Moohan M, Tunstall-Pedoe H. Self-reported smoking, cigarette yields and inhalation biochemistry related to the incidence of coronary heart disease: results from the Scottish Heart Health Study. J Eoronary heart disease: results from themiol Biostat 1999;4:285-95.

16 LaCroix AZ, Lang J, Scherr PA, et al. Smoking and mortality among older men and women in three communities. N Engl J Med 1991;324:1619-25

17 Seltzer CC. Framingham study data and "established wisdom" about cigarette smoking and coronary heart disease. J Clin Epidemiol 1988;42:743-50.

18 Doll R, Gray R, Hafner B, et al. Mortality in relation to smoking: 22 years' observations on female British doctors. BM 1980;280:967-71.

19 Thun MJ, Day Lally CA, Calle EE, et al. Excess mortality among cigarette smokers: changes in a 20 -year interval. Am J Public Health 1995;85:1223-30.

20 Baron JA, La Vecchia C, Levi F. The antiestrogenic effect of cigarette smoke in women. Am J Obstet Gynecol 1990;162:502-14.

21 Prescott E, Bjerg AM, Andersen PK, et al. Gender difference in smoking effects on lung function and risk of hospitalization for COPD: results from a Danish longitudinal population study. Eur Respir J 1997;10:822-7.

22 Becklake MR, Kauffmann F. Gender differences in airway behaviour over the human life span. Thorax 1999;54:1119-38. 